Results: Compared to the Vehicle, all treatments significantly reduced $(p<0.001)$ arthritic score with a reduction of the arthritic score evaluated between $40 \%$ (for methotrexate) and $70 \%$ (for diclofenac) (figure 1. Compared to the vehicle, the radiographic score was improved by Naproxene, Diclofenac, Celecoxib, Glucocorticoids, Etanercept $(p<0.001)$ but not by methotrexate. Compared to Etanercept, Naproxene and diclofenac showed less radiological structural changes $(\mathrm{p}<0.01$ ) (figure 2).

Conclusions: Our study demonstrates for the first time that an early treatment with NSAIDs, excluding COX2 selective inhibitor, is more beneficial than Etanercept on the radiological damages in adjuvant induced arthritis. The close efficacy of all drugs on the arthritis score suggests that the beneficial impact of NSAID is not only driven by their impact on the systemic inflammation. NSAIDs should be used during the window of opportunity.

Disclosure of Interest: None declared

DOI: 10.1136/annrheumdis-2017-eular.2611

\section{FRI0045 ORAL MICROBIOME PROFILE IN RHEUMATOID ARTHRITIS PATIENTS: ASSOCIATION BETWEEN TONGUE BIOFILM PORPHYROMONAS GINGIVALIS AMOUNT AND DISEASE ACTIVITY}

F. Ceccarelli ${ }^{1}$, G. Orrù ${ }^{2}$, A. Pilloni ${ }^{3}$, I. Bartosiewicz ${ }^{4}$, C. Perricone ${ }^{4}$, E. Martino ${ }^{5}$, R. Lucchetti ${ }^{6}$, S. Fais ${ }^{2}$, M. Vomero ${ }^{4}$, M. Olivieri ${ }^{4}$, M. Di Franco ${ }^{4}$, R. Priori ${ }^{4}$, V. Riccieri ${ }^{4}$, A. Sili Scavalli ${ }^{4}$, R. Scrivo ${ }^{4}$, C. Alessandri ${ }^{4}$, F. Conti ${ }^{4}$, A. Polimeni ${ }^{4}$, G. Valesini ${ }^{4}{ }^{1}$ Reumatologia, Dipartimento di Medicina Interna e Specialità Mediche, Sapienza Università di Roma, Rome, ${ }^{2}$ Molecular Biology Service, University of Cagliari "Ospedale S. Giovanni di Dio", Cagliari, ${ }^{3}$ Odontoiatria, Dipartimento di Scienze Odontostomatologiche e Maxillo Facciali, Sapienza Università di Roma, Rome; ${ }^{4}$ Reumatologia, Dipartimento di Medicina Interna e Specialità Medica; ${ }^{5}$ Odontoiatria, Dipartimento di Scienze Odontostomatologiche e Maxillo Facciali, Sapienza Università di Roma; ${ }^{6}$ Reumatologia, Dipartimento di Medicina Interna e Specialità Medica, Sapienza, Università di Roma, Roma, Italy

Background: $P$. gingivalis is a Gram-negative anaerobic bacterium usually located in the oral cavity, as component of microbiome. Next to the established association with oral cavity diseases, such as periodontitis and halitosis, in the last years a growing interest has been addressed to its implication in the development of autoimmune diseases, such as Rheumatoid Arthritis (RA). The ability of $P$. gingivalis to citrullinate peptides is the most relevant link with RA. Indeed, this bacterium has several virulence factors directly contributing to its chronic inflammation regardless of citrullination. Data from the literature demonstrated the ability of $P$. gingivalis in inducing the production of several inflammatory cytokines, such as TNF, IL6 and IL17, through the TLR signaling pathways.

Objectives: In the present case-control study, we aimed at analysing tongue microbiome in a large RA cohort, focusing on the evaluation of $P$. gingivalis presence and quantification.

Methods: We enrolled 143 RA patients (1987 ACR criteria; M/F 32/111, mean \pm SD age $57.5 \pm 19.8$ years, mean $\pm S D$ disease duration $155.9 \pm 114.7$ months); 36 periodontitis $(\mathrm{M} / \mathrm{F} 11 / 25$, mean $\pm S D$ age $56 \pm 9.9$ years, mean $\pm S D$ disease duration $25.5 \pm 20.9$ months); 57 (M/F 12/45, mean \pm SD age $61.4 \pm 10.9$ years, mean \pm SD disease duration $62.3 \pm 66.9$ months) affected by knee osteoarthritis or fibromyalgia (control subjects - CS). All subjects underwent a clinical evaluation in order to assess disease activity by DAS28. Blood serum samples were obtained to evaluate the presence of ACPA by a commercial ELISA kit. Finally, a standard cytologic swab to collect tongue biofilm samples was performed and the presence of $P$. gingivalis was evaluated by PCR method.

Results: The prevalence of $P$. gingivalis resulted significantly higher in RA and $P D$ patients in comparison with $C S(P=0.01$ and $P=0.003$, respectively). No correlation between bacterium presence and ACPA was found. When evaluating the percentage of $P$. gingivalis on the total tongue biofilm, we observed a significant correlation between this measure and DAS28 values $(r=0.4, P=0.01)$. Furthermore, RA patients in DAS28 remission showed a significantly lower prevalence of $P$. gingivalis in comparison with non-remission patients $(P=0.02)$. Conclusions: In the present study, for the first time we assessed the prevalence of $P$. gingivalis, i.e. its percentage on the total tongue biofilm, in a large RA cohort. A significant correlation between the amount of $P$. gingivalis on total tongue biofilm and disease activity was observed. There was no association with ACPA, suggesting that this bacterium, beyond citrullination, could be implicated in triggering a pro-inflammatory state in RA.

Disclosure of Interest: None declared

DOI: 10.1136/annrheumdis-2017-eular.5034

\section{FRI0046 IDENTIFICATION OF HERV-K ENV SURFACE PEPTIDES HIGHLY RECOGNIZED IN RA PATIENTS}

G.L. Erre ${ }^{1}$, G. Mameli ${ }^{2}$, D. Cossu ${ }^{2}$, S. Mura ${ }^{3}$, A. Piras ${ }^{3}$, M.L. Cadoni ${ }^{1}$, G. Buscetta ${ }^{3}$, N. Mundula ${ }^{3}$, E. Colombo ${ }^{3}$, M.G. Longu ${ }^{1}$, L.A. Sechi ${ }^{2}$,

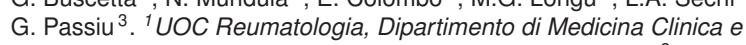
Sperimentale, Azienda Ospedaliero-Universitaria di Sassari; ${ }^{2}$ Scienze Biomediche, Istituto di Microbiologia; ${ }^{3}$ UOC Reumatologia, Dipartimento di Medicina Clinica e Sperimentale, Università degli Studi di Sassari, Sassari, Italy

Background: Endogenous Retroviruses (HERV) are believed to be pathogenic in several autoimmune diseases. Among them, HERV-K viruses have been recently reported to be involved in the pathogenesis of rheumatoid arthritis (RA).

Objectives: In this study we have explored the role of humoral immune response against HERV-K as a potential pathogenetic mechanism in RA.

Methods: Four different peptides from the extracellular portion of the env protein of HERV-K (env-su 19-37, env-su 109-26, env-su 164-205, env-su 209-226) were selected by bioinformatic analysis on the basis of their putative immunogenicity. Indirect ELISA was then carried out to quantify antibodies against those peptides on blood samples from RA patients and healthy controls $(\mathrm{HC})$. Differences between the two groups were analysed using the Mann-Whitney rank-sum and chi-square tests. Potential correlations between RA laboratory, clinical descriptors and IgGs levels were explored by bivariate regression analysis.

Results: Seventy consecutive RA patients and seventy-one HC crossed by age and sex were enrolled in the study. Serum autoantibodies against three out of the four tested peptides, anti HERV-Ksu ${ }_{19-37}$, HERV-K env-su ${ }_{109-126}$ and HERV-K env-su ${ }_{205-226}$, were significantly more prevalent in RA than in $\mathrm{HC}(19 \%$ vs $3 \%, p=0.0001 ; 9 \%$ vs $3 \%, p=0.0001$; and $6 \%$ vs $3 \%, p=0.0001$ respectively) (See Fig. 1)

Subgroup analysis showed no association between anti-HERV-K peptide humoral response and clinical, serological and clinimetric RA disease descriptors.
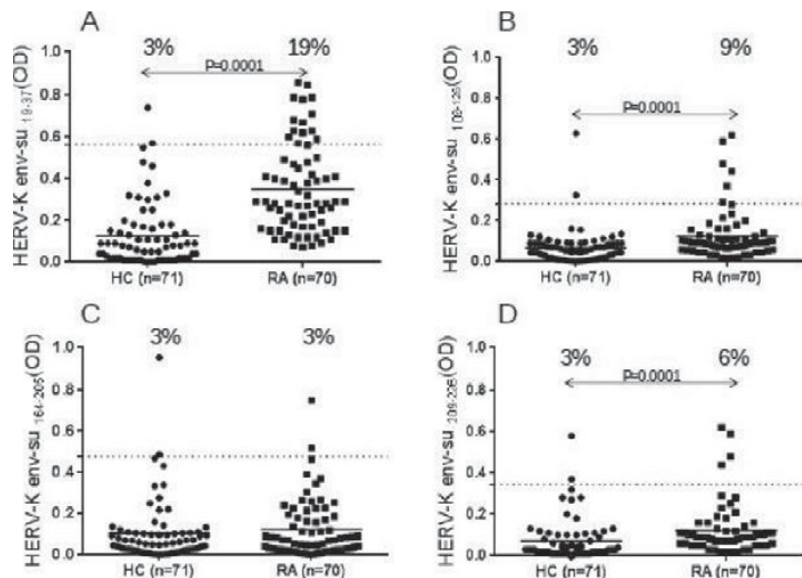

D

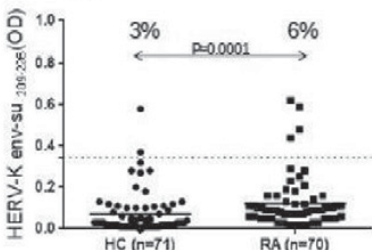

Conclusions: Serum from RA patients in our series significantly reacted against different HERV-K peptides in comparison to the general population suggesting a role for the HERV-K related, secondary antigenic driven immune response in the pathogenesis of RA. Further studies are needed to confirm these results and to explore the role of HERV-K surface peptides as potential therapeutic targets.

Disclosure of Interest: None declared

DOI: 10.1136/annrheumdis-2017-eular.2043

\section{FRI0047 ELEVATED 14-3-3ETA LEVELS PREDICT WORSE RADIOGRAPHIC OUTCOMES IN PATIENTS WITH RECENT-ONSET INFLAMMATORY ARTHRITIS IN CLINICAL REMISSION}

N. Carrier ${ }^{1}$, M.-P. Garant ${ }^{2}$, A. Marotta ${ }^{3}$, A.J. De Brum Fernandes ${ }^{4}$, P. Liang $^{4}$, A. Masetto ${ }^{4}$, Y. Gui ${ }^{5}$, J. Savill ${ }^{5}$, S. Michienzi ${ }^{5}$, W.P. Maksymowych ${ }^{6}$, G. Boire ${ }^{4}$ ${ }^{1}$ Division of Rheumatology, CIUSSS de l'Estrie-CHUS; ${ }^{2}$ Biostatistics, Centre de recherche du CHUS, Sherbrooke; ${ }^{3}$ Auguex Life Sciences Crop., Vancouver; ${ }^{4}$ Medicine, Division of Rheumatology, Université de Sherbrooke, Sherbrooke;

${ }^{5}$ Augurex Life Sciences Corp., Vancouver; ${ }^{6}$ Medicine, University of Alberta, Edmonton, Canada

Background: $14-3-3 \eta$ is a joint-derived serum protein that up-regulates proinflammatory factors. We have previously reported that baseline $14-3-3 \eta$ levels

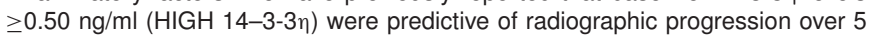
years.

Objectives: Our objective was to verify if the persistence of HIGH 14-3-3n at 18 months in recent-onset polyarthritis patients in REMISSION predicts more rapid radiographic progression over the following years, up to 42 months.

Methods: Serum 14-3-3 $\eta$ titres were assessed at baseline and at 18 months into disease, a median of 14 months after diagnosis and initiation of treatment. Three definitions of "clinical remission" at 18 months were used: Swollen Joint Count $(\mathrm{SJC})=0 ; \mathrm{SJC}+$ Tender Joint Count $(\mathrm{TJC})=0 ; \mathrm{ACR} / \mathrm{EULAR}$ Boolean definition. The progression of radiographic damage (Erosion and Total Sharp/van der Heijde (SvH) scores) in patients with LOW $(<0.50 \mathrm{ng} / \mathrm{ml})$ or $\mathrm{HIGH}(\geq 0.50 \mathrm{ng} / \mathrm{ml}) 14-3-3 \eta$ were compared using the Mann-Whitney test. $P$ values $<0.05$ were considered significant.

Results: Out of 331 patients, $36.0 \%$ of which had HIGH 14-3-3n at Baseline, 308 had complete data up to 5 years. Median age was 60 years, $62 \%$ women. Depending on the stringency of the definition used, variable numbers of patients reached remission at 18 months: $162(53 \%)$ had SJC=0; $108(35 \%) \mathrm{SJC}+\mathrm{TJC}=0$; and $56(18 \%)$ Boolean.

Remission at 18 months was negatively associated with persistence of HIGH 
14-3-3n since HIGH 14-3-3n were then present in 32/162 (19.7\%) SJC $=0$ patients; 22/108 (20.4\%) SJC+TJC=0 and 13/56 (23.2\%) Boolean.

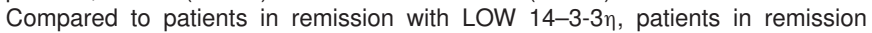

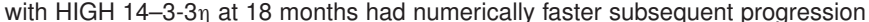
with all definitions. For example, in patients with Boolean remission, mean (SD) erosion progression over 42 months was $7.2 \pm 13.1$ vs $1.5 \pm 3.3$ and mean (SD) progression of Total score $9.2 \pm 14.5$ vs $2.8 \pm 4.4$ units (Figure).

However, due to low numbers and limited power, differences in progression were statistically significant only for the less strict definitions of remission and only over the following year: Erosions $(\mathrm{SJC}=0, \mathrm{p}=0.0042$, $\mathrm{SJC}+\mathrm{TJC}=0, \mathrm{p}=0.0236)$, Total score $(\mathrm{SJC}=0, \mathrm{p}=0.0146$; with a trend for $\mathrm{SJC}+\mathrm{TJC}=0, \mathrm{p}=0.077$ ).

None of the comparisons over 42 months or of those involving Boolean reached significance.

Figure. Progression of Erosion Sharp/van der Heijde score in patient s in Boolean remission at 18 months.

A. $14-3-3 \eta<0.50 \mathrm{ng} / \mathrm{ml}$ at 18 months. B. $14-3-3 \eta \geq 0.50 \mathrm{ng} / \mathrm{ml}$ at 18 months.

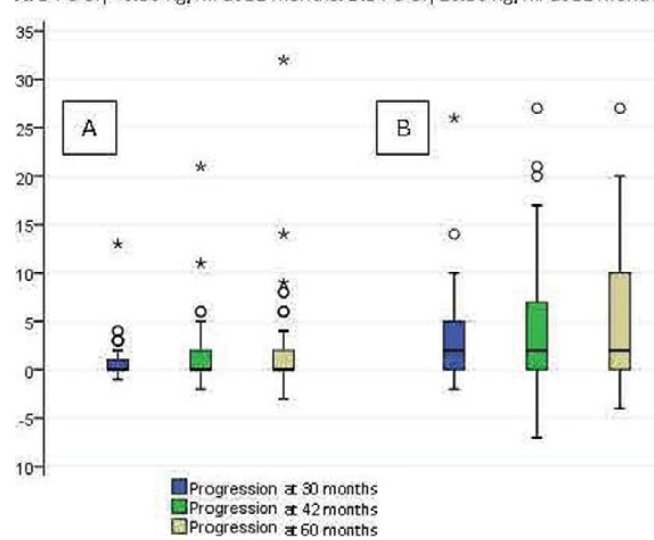

Conclusions: The persistence of $14-3-3 \eta$ levels $\geq 0.50 \mathrm{ng} / \mathrm{ml}$ appears to be associated with a lower probability of reaching remission in polyarthritis patients. $14-3-3 \eta$ levels $>0.50 \mathrm{ng} / \mathrm{ml}$ in patients in clinical remission appear to be associated with more rapid radiographic (especially erosive) progression over the following year. A larger study is required to validate these findings, especially with the most stringent criterion of Boolean remission.

Disclosure of Interest: N. Carrier: None declared, M.-P. Garant: None declared, A. Marotta Employee of: Augurex Life Sciences Corp., A. De Brum Fernandes Grant/research support from: AJdBF is part of the Centre de Recherche Clinique from the CHUS, which received a team grant from the Fonds de Recherche en Santé-Québec, P. Liang: None declared, A. Masetto: None declared, Y. Gui Employee of: Augurex Life Sciences Corp., J. Savill Employee of: Augurex Life Sciences Corp., S. Michienzi Employee of: Augurex Life Sciences Corp., W. Maksymowych Consultant for: Augurex Life Sciences Corp., G. Boire Grant/research support from: GB is part of the Centre de Recherche Clinique from the CHUS, which received a team grant from the FRSQ. GB is the recipient of CIHR grant MOP-110959. Since 2007, the Sherbrooke EUPA cohort has also received financial support from the Canadian ArTritis CoHort (CATCH), a study designed and implemented by investigators and financially supported via unrestricted research grants initially by Amgen Canada Inc

DOI: 10.1136/annrheumdis-2017-eular.4085

\section{FRI0048 THE ANTI-CD20 ANTIBODY RITUXIMAB REDUCES THE INFLAMMATORY AND PROTHROMBOTIC PROFILE OF LEUKOCYTES FROM RHEUMATOID ARTHRITIS PATIENTS AND MODULATES THE ACTIVITY OF ENDOTHELIAL CELLS}

I. Cecchi ${ }^{1}$, C. Perez-Sanchez ${ }^{2}$, P. Ruiz-Limon ${ }^{2}$, I. Arias de la Rosa ${ }^{2}$, M.C. Abalos-Aguilera ${ }^{2}$, Y. Jimenez-Gomez ${ }^{2}$, R. Ortega ${ }^{2}$, E. Collantes-Estevez ${ }^{2}$, A. Escudero ${ }^{2}$, N. Barbarroja ${ }^{2}$, S. Sciascia ${ }^{1}$, C. Lopez-Pedrera ${ }^{2}$. ${ }^{1}$ Department of Clinical and Biological Sciences, Center of Research of Immunopathology and Rare Diseases - Coordinating Center of Piemonte and Valle d'Aosta Network for Rare Diseases, Turin, Italy; ${ }^{2}$ GC-5/Rheumatology, IMIBIC/Reina Sofia Hospital/University of Cordoba, Cordoba, Spain

Background: Rituximab (RTX) has been shown to be successful in the treatment of rheumatoid arthritis (RA), indicating that $B$ cells have an important role in this disease.

Objectives: The present study was undertaken to investigate the mechanisms of action of RTX on the immune and endothelial cells (EC) of the vascular system in the setting of RA.

Methods: Purified lymphocytes from five RA patients with high disease activity were treated with RTX $(1 \mathrm{ug} / \mathrm{mL})$ for 24 hours. Then, the depletion of B cells was assessed by flow cytometry, and the changes occurred in the inflammatory profile of T-lymphocytes was analysed by RT-PCR. In a second set of experiments, to evaluate the influence of B-cell depletion on the inflammatory/prothrombotic profile of cells belonging to the vascular system, supernatants from cultured lymphocytes of RA patients in the presence or in the absence of RTX were added to isolated monocytes from AR patients and to cultured endothelial cells. The response to RTX was then examined.

Results: As expected, RTX promoted a significant depletion of B-cells. In parallel, the inflammatory profile of $T$ lymphocytes from RA patients was downregulated, as shown by a significant drop of IL-1, IL-6, IL-17, IFN and TNF expression levels, thus suggesting that the anti-inflammatory effects of RTX might be related to B cell depletion. Supernatants from RTX-treated lymphocytes further abridged the prothrombotic profile of RA-monocytes, promoting a significant inhibition of TF, MCP-1, IL-8, IL-1 and VEGF-A gene expression. Moreover, endothelial cells, activated after treatment with supernatants from cultured RA-lymphocytes, showed reduced expression of cell-adhesion molecules (i.e. V-CAM, I-CAM, E-Selectin) and pro-thrombotic factors (i.e. TF, VEGF, IL-8) after treatment with supernatants from cultured RA-lymphocytes in the presence of RTX.

Conclusions: Overall, these results reveal that depletion of B-cells by RTX in RA influences the inflammatory profile of $\mathrm{T}$ lymphocytes, as well as their interaction with monocytes and ECs, thus modulating the inflammatory and prothrombotic shape of vascular cells in the setting of RA.

Acknowledgements: Supported by CTS-794, ISCIII (PI15/01333; RIER RD16/0012/0015)

Disclosure of Interest: None declared

DOI: 10.1136/annrheumdis-2017-eular.4916

\section{FRI0049 FC GAMMA RECEPTOR IV ENHANCES BONE EROSION IN EXPERIMENTAL ARTHRITIS BY PROMOTING INFLUX OF PMNS}

I. Di Ceglie ${ }^{1}$, G. Ascone ${ }^{1}$, M. van den Bosch ${ }^{1}$, J.S. Verbeek ${ }^{2}$, P. van der Kraan ${ }^{1}$, P. van Lent ${ }^{1}$. ${ }^{1}$ Experimental Rheumatology, Radboud University Medical Center, Nijmegen; ${ }^{2}$ Leiden University Medical Center, Leiden, Netherlands

Background: $\mathrm{Fc} \gamma \mathrm{Rs}$ are involved in regulation of synovial activation and bone destruction during immune complex (IC)-mediated arthritis. The balance between activating $\mathrm{Fc}_{\mathrm{c}} \mathrm{Rs}\left(\mathrm{Fc}_{\mathrm{c}} \mathrm{RI}, \mathrm{III}\right.$ and IV) and inhibiting $\mathrm{Fc}_{\mathrm{c}} \mathrm{RII}$ determines synovial activation. Here we investigated the particular role of activating Fc $\gamma$ RIV in bone erosion in IC-mediated antigen induced arthritis (AIA) by comparing $\mathrm{Fc} \gamma \mathrm{RI}, \mathrm{II}, \mathrm{III}, \mathrm{IV} \mathrm{V}^{-/-}$mice, $\mathrm{Fc} \gamma \mathrm{RI}, \mathrm{II}, \mathrm{III}{ }^{-/-}$mice and wild type controls (WT).

Objectives: To investigate the role of $\mathrm{Fc} \gamma \mathrm{RIV}$ in bone erosion during experimental arthritis.

Methods: AIA was induced by injection of mBSA into knee joints of mice previously immunized with mBSA/CFA. Joint inflammation, bone destruction, number of $\mathrm{TRAP}^{+}$osteoclasts and S100A8/A9 positive cells was determined using histology and immunohistochemistry. In vitro osteoclastogenesis was assessed using TRAP staining.

Results: Seven days after induction of AIA, we observed decreased inflammation and bone erosion in the knee joints of $F_{c} \gamma \mathrm{RI}_{1} \mathrm{II}, \mathrm{III}, \mathrm{IV}^{-/-}$mice compared to WT. The ability of bone marrow cells of $\mathrm{Fc} \gamma \mathrm{RI}, \mathrm{II}, \mathrm{III}, \mathrm{IV}^{-/-}$mice to differentiate into osteoclasts in vitro was comparable to the one of WT controls. Moreover, we observed comparable numbers of $\mathrm{TRAP}^{+}$osteoclasts on the bone surface of $\mathrm{Fc} \gamma \mathrm{RI} / \mathrm{II} / \mathrm{III} / \mathrm{IV}^{-/-}$and WT arthritic mice, suggesting that the observed decrease in bone erosion is mainly caused by a reduced osteoclast activity, rather than decreased osteoclast number. However, in contrast to $\mathrm{Fc} \gamma \mathrm{RI} / \mathrm{II} / \mathrm{III} / \mathrm{IV}^{-/}$, $\mathrm{AIA}$ induction in knee joints of $\mathrm{Fc} \gamma \mathrm{RI} / \mathrm{II} / \mathrm{III} \%$ resulted in increased bone erosion and inflammation compared to WT, highlighting the possible crucial role of Fc $\gamma \mathrm{RIV}$ in the pathology. Interestingly, the number of PMNs infiltrated in the knee joint of $\mathrm{FC} \gamma \mathrm{RI} / \mathrm{II} / \mathrm{III}^{-/-}$resulted increased, whereas it was decreased in the knee joints of $\mathrm{Fc} \gamma \mathrm{RI} / \mathrm{II} / \mathrm{III} / \mathrm{IV}^{-/-}$compared to their WT controls. This observation suggests that particularly Fc $\gamma$ RIV is involved in regulating influx of PMNs. PMNs are potent producers of alarmins S100A8/A9 which are described to promote osteoclast activity. In line the number of S100A8/A9 positive cells in synovium was increased in $\mathrm{Fc} \gamma \mathrm{RI} / \mathrm{II} / \mathrm{III}^{-/-}$while decreased in $\mathrm{Fc} \gamma \mathrm{RI} / \mathrm{II} / \mathrm{III} / \mathrm{IV}^{-/-}$, compared to their WT control. Conclusions: Fc $\gamma$ RIV promotes bone erosion in AIA by enhancing influx of PMNs within the synovium. PMNs are potent producers of S100A8/A9 which has been described to induce osteoclast activity.

Disclosure of Interest: None declared

DOI: 10.1136/annrheumdis-2017-eular.5386

\section{FRI0050 TYPE II COLLAGEN SECRETED FROM ARTICULAR CHONDROCYTES IS MAINLY DESTROYED BY CATHEPSIN S IN RA MICE}

J. Zhao, Q. Huang, H. Ren, M. Yang. Department of Rheumatology, Nanfang Hospital, Southern Medical University, Guangzhou, China

Background: Mast cells have long been recognized to increase strikingly in number in the synovial membrane of rheumatoid arthritis (RA), accounting for $5 \%$ of the surface synovial membrane cells. Type II collagen has the longest half-life in cartilage matrix. The main cells which might affect articular cartilage in RA are synovial fibroblasts, synovial macrophages and mast cells. The latter two could express cathepsin S.

Objectives: We aimed to find the cells which have the biggest influence on type II collagen secreted from articular chondrocytes and the possible mechanisms in RA mice.

Methods: Four types of cells from collagen-induced arthritis model-established C57BL/6 mice were primary cultured, including synovial fibroblasts, peritoneal 